\title{
LIBERTAÇÃO VERSUS HEGEMONIA: APROXIMAÇÕES ENTRE PAULO FREIRE E ANTONIO GRAMSCI
}

\author{
FREEDOM VERSUS HEGEMONY: APPROACHES BETWEEN PAULO FREIRE AND ANTONIO \\ GRAMSCI
}

Alan Caldas Simões ${ }^{1}$

SIMÕES, A. C. Libertação versus Hegemonia: Aproximação entre Paulo Freire e Antonio Gramsci. Akrópolis Umuarama, v. 25, n. 1, p. 61-68, jan./jun. 2017.

DOI: 10.25110/akropolis.v25i1.6675

REsumo: O presente artigo tem como objetivo realizar aproximações teóricas entre as ideias de Paulo Freire e Antônio Gramsci quanto às suas concepções de sociedade e educação. Dessa forma, problematizamos sobre as possíveis relações entre tais autores, enfocando os modos e percursos que definem para transformação individual e social do homem. No campo educativo, Gramsci apresenta uma proposta ampla e sistemática, em que identifica a articulação entre educação e política em nível individual e coletivo. Em Freire, estas noções se encontram fragmentadas na noção de conscientização e libertação. No campo social enquanto para Gramsci o processo de transformação da sociedade assume uma ótica política de enfrentamento, em Freire esta noção é marcada pela fé e pelo cristianismo. Por fim, esperamos que nosso trabalho fomente questões sobre as possibilidades de aproximações teóricas e práticas entre esses dois autores que influenciaram o pensamento educativo do século XXI.

Licenciado em Música pela Universidade Federal do Espírito Santo (UFES). Mestre em Educação Musical pela Universidade Federal do Rio de Janeiro (UFRJ). Doutorando em Educação Musical pela Universidade Federal de Minas Gerais (UFMG).

Endereço para correspondência: Rua Mário Jorge Assef, 300, Itapebussu, Guarapari, Espírito Santo. CEP: 29210-180.

E-mail: alanmpb@yahoo.com.br

Vínculo institucional: Doutorando em música pela UFMG. Atualmente é professor efetivo de Artes do Instituto Federal do Espírito Santo.

PalaVRas-Chave: Antonio Gramsci; Concepções de educação e sociedade; Paulo Freire.

ABSTRACT: This article aims to make theoretical approaches between the ideas of Paulo Freire and Antônio Gramsci regarding their conceptions of society and education. In this way, it problematizes the possible relations between these authors, focusing on the ways and routes that define individual and social transformations. In the educational field, Gramsci presents a broad and systematic proposal, where he identifies the articulation between education and politics at both individual and collective levels. In Freire, these notions are fragmented within the notion of awareness and freedom. In the social field, while Gramsci considers that the process of transforming a society assumes a confrontation political view, in Freire, this notion is marked by faith and Christianity. Finally, it is expected that this work fosters questions regarding the possibilities of theoretical and practical approaches between these two authors that have influenced the educational thinking of the $21^{\text {st }}$ century. KEYWORDS: Antonio Gramsci; Conceptions of education and society; Paulo Freire. 


\section{INTRODUÇÃO}

O presente trabalho tem como objetivo realizar uma aproximação teórica entre as ideias de Paulo Freire (1921-1997) e Antônio Gramsci (1891-1937) quanto às suas concepções de sociedade e educação. Paulo Freire foi um educador e pedagogo brasileiro nascido em Pernambuco. Dedicou sua vida à pesquisa e a práticas educativas que possuíam como eixo central a possibilidade de transformação do mundo por meio da evolução individual e coletiva das consciências. Dentre as suas principais contribuições para o campo teórico e prático da educação, encontram-se a criação de um método de alfabetização para adultos e uma pedagogia crítica, fundamentado no respeito aos saberes do educando, na curiosidade epistemológica, na amorosidade, na liberdade, e no diálogo como forma de superação da opressão e como marca indissolúvel da fé nos homens (FREIRE, 1987, 1992, 1996, 1999, 2006). Sua pedagogia está intimamente ligada ao existencialismo cristão e à síntese existencial-culturalista advinda dos isebianos históricos (PAIVA, 1986, p. 78).

O existencialismo cristão é uma abordagem filosófica existencialista da teologia cristã cuja proposta define que cada pessoa deve fazer escolhas independentes, que compreendem, em seguida, a sua existência. Defende ainda que a essência humana corresponde a um atributo de Deus (ABBAGNANO, 1982, 402406). Já o existencialismo é uma doutrina filosófica que possui foco na existência e valoriza a liberdade individual. Dessa forma, define que as pessoas são diferentes entre si e livres para serem o que quiserem ser, assumindo a responsabilidade por suas escolhas e por tudo que as cercam (a sociedade, a política, a nação). Já o culturalismo define que a cultura condiciona o comportamento psicológico do indivíduo, sua maneira de pensar e a forma como percebe o seu entorno (ABBAGNANO, 1982, 402-406).

Antonio Gramsci foi um pensador, filósofo e político italiano nascido na Sardenha. Sua principal preocupação como filósofo e ativista político foi compreender como se desenvolvem as formas de dominação nas sociedades modernas. Segundo Gramsci, as classes dominantes exercem o controle social por meio da economia e da política; entretanto, tal dominação vai além desses dois campos, exercendo sua influência fundamentalmente no campo da cultura. Gra- msci denominou como hegemonia a dominação exercida por meio do domínio econômico e da direção intelectual e moral, exercida com o consentimento dos grupos subalternos.

Portanto, a hegemonia para Gramsci é a forma como as classes dominantes submetem a classe trabalhadora à sua dominação não apenas por meio da força, mas também pela obtenção do seu consentimento. O domínio com o consentimento dos governados é um dos traços marcantes do conceito de hegemonia. Para obter o consentimento dos grupos subalternos, os grupos dominantes atuam no âmbito da educação, dos partidos políticos, da religião dos meios de comunicação, enfim, das organizações da sociedade civil que se multiplicaram enormemente desde o início do século $X X$.

Tanto Freire quanto Gramsci foram grandes humanistas de seus tempos. Com o objetivo de compreender a realidade e intervir sobre ela, ambos buscaram formular concepções teóricas e práticas sobre a sociedade e sobre o ser humano. Apesar de não serem contemporâneos, as ideias de Gramsci, possivelmente, chegaram até Freire durante seu período de exílio no Chile, onde se aproximou teoricamente do materialismo histórico desenvolvido por Karl Marx (18181883) e Friederich Angels (1820-1895) (MESQUIDA; ROSSETE; PASCHOAL, 2006; SILVA; BARBOSA, 2013).

\section{DESENVOLVIMENTO: INFLUÊNCIAS TEÓ- RICAS}

No período do cárcere, Gramsci formulou uma teoria para instauração de uma nova hegemonia no mundo que envolve diretamente os processos de conquista, concessão e direcionamento político da sociedade. Estritamente, não há um método gramsciano, tal qual podemos falar em um método freiriano. Entretanto, a origem da formulação teórica de Freire é difusa, embora possa ser analisada como resultado das discussões nacionalista-desenvolvimentistas oriundas do trabalho do Instituto Superior de Estudos Brasileiros (ISEB) na década de 50 e 60 (PAIVA, 1986). O ISEB foi criado para servir de instrumento para uma ação eficaz no processo político do país, reunindo intelectuais, de distintas orientações teóricas e ideológicas - nele conviviam liberais, comunistas, socialdemocratas e católicos progressistas. Pode-se dizer que no Instituto se confrontavam simpatizantes do 
marxismo, do existencialismo de Sartre, da fenomenologia de Jaspers e de outras correntes filosóficas e sociológicas. No entanto, os intelectuais convergiam na convicção de que, por meio do debate e do confronto das ideias, seria possível formular um projeto ideológico comum para - Brasil. O nacional-desenvolvimentismo foi, então, concebido como essa ideologia-síntese. Contudo, a trajetória teórica de Freire é marcada "[...] pela sua história pessoal e por características próprias" (PAIVA, 1986, p. 18) aliadas à sua "intuição e sensibilidade" (PAIVA, 1986, p. 17).

Assim, suas formulações teóricas apresentam um caráter pessoal em conformidade com as necessidades de sua própria práxis (BARRETO, 1998, p. 16). Como exemplo dessa característica própria, Strech, Redin e Zitkoski evidenciam a apropriação que Freire fez do postulado hegeliano, mostrando que:

[...] Freire não se interessava por ações intelectuais estabelecidas a priori e distanciadas da práxis educacional cotidiana, atitude esta que se estendeu à apropriação que ele fez da dialética hegeliana. Nesse sentido, tanto os críticos como os defensores de Freire reconhecem que tal assimilação nunca ocorreu de forma exclusiva e dogmática, o que acabou por desenvolver caminhos próprios de interpretação do legado de Hegel. (STRECH; REDIN; ZITKOSKI, 2016, p. 203)

Este movimento teórico pode ser percebido em Freire não apenas se tratando de Hegel, mas na maior parte dos teóricos citados por ele em suas obras, em que realiza o mesmo movimento discursivo de assimilação própria das teorias. Tal processo permitiu a Freire analisar a sociedade de maneira original, mas ao mesmo tempo evidenciando limites para a sua teoria do conhecimento, o que fomentou uma série de críticas às bases teóricas de seu trabalho.

Tanto em Freire como em Gramsci, há a influência do marxismo, apesar de em Freire esta influência permanecer como um "debate inconcluso" na academia e necessitar ser analisada a partir dos pressupostos do seu método de ensino e os postulados centrais do materialismo histórico dialético (STRECK; REDIN; ZITKOSKI, 2016, p. 254). Em metáfora criada por Marx, a sociedade capitalista estaria organizada em infraestrutura (economia) e superestrutura (ideologia), relacionadas dialeticamente. A metáfora de Marx foi convertida numa "realidade" pela visão economicista, segundo a qual a infraestrutura determinaria a superestrutura (MARX, 1993). Freire considerava que infra e superestruturas se relacionavam dialeticamente, como podemos conferir na análise abaixo:

[...] a estrutura social não resultava da 'soma (nem na justaposição) da infraestrutura com a supraestrutura', mas da 'dialetização entre as duas', Freire reitera o 'indiscutível papel' que uma 'revolução cultural' poderia jogar no 'processo de libertação das classes oprimidas. (STRECK; REDIN; ZITKOSKI, 2016, p. 255)

Criticando a interpretação economicista da metáfora de Marx sobre a sociedade, Gramsci retoma o pensamento de Marx para mostrar que a superestrutura não está desvinculada da estrutura e ambas têm a mesma importância na transformação da sociedade. Então, ele cita trechos de Marx em que este afirma que os homens tomam consciência das questões políticas e sociais no terreno da superestrutura. Indo mais além, Gramsci formula o conceito de bloco histórico, para afirmar a unidade entre estrutura econômica e superestrutura político-ideológica.

Em seu método de alfabetização de adultos, Freire evidencia a importância de valorizar a cultura do educando como meio de problematização da realidade (FREIRE, 2006). Por meio dessa problematização, o sujeito desperta sua consciência sobre o mundo à sua volta e sobre o seu papel na sua transformação. Portanto, para Freire, a cultura popular estaria em igualdade com a cultura erudita, sendo esta posição negada aos oprimidos pelos opressores (FREIRE, 1987). Para ambos os autores, a revolução cultural que deve ocorrer nas classes oprimidas ou classes subalternas implica um processo de evolução da consciência. Freire destaca ainda, a passagem do nível de consciência ingênua para a consciência crítica (FREIRE, 2006), enquanto Gramsci evidencia a necessidade de elevação cultural das massas do nível do "bom senso" (conhecimento de senso comum) para o "nível filosófico" (concepção organizada do mundo) (DORE, 2016). Dessa forma, enquanto Freire defende uma educação cultural por meio da "leitura do mundo", Gramsci defende a elevação cultural por meio de um processo de "alfabetização cultural".

O processo de conscientização das massas, para Freire implica também a realização da 
práxis e o despertar da consciência que permite um engajamento que pode levar as massas populares a um comprometimento com a realidade. A transformação da consciência implica a práxis, que pode ser entendida, em termos freirianos, como "uma síntese entre teoria-palavra e ação" (STRECK; REDIN; Zitkoski, 2016, p. 325). Em ambos os pensadores, a evolução da consciência não precede e nem sucede a transformação da realidade, pois ambos os processos são concomitantes, uma vez que a práxis é o resultado da união entre reflexão e ação com vistas à transformação da realidade.

\section{PAPEL DA ESCOLA}

Para Gramsci "[a] escola é o instrumento para elaborar os intelectuais de diversos níveis" (GRAMSCI, 1999, p. 19). Nessa formulação, Gramsci mostra que o trabalho educativo visa a formar intelectuais para os grupos sociais. Gramsci pensa a formação de intelectuais vinculados aos grupos subalternos quando propõe a criação de uma escola unitária, de formação humanista, que possua como princípio educativo a "[...] unidade entre teoria e prática, a formação de dirigentes para a conquista da hegemonia." (DORE, 2014, p. 311). Gramsci tem como referência prática e teórica a atividade editorial de revistas ("revistas tipo"), pois por muito tempo trabalhou com revistas. De sua experiência ele propõe para a escola atividades semelhantes àquelas que ocorriam na atividade editorial como um relevante instrumento didático para elevar e organizar a cultura das classes subalternas (DORE, 2007).

No campo educativo Freire propõe superar o que denomina "educação bancária" por uma educação problematizadora que visa à libertação do indivíduo (FREIRE, 1987, 1992, 1996, 2006). Segundo Freire, a educação bancária se caracteriza: pela rigidez nas relações de ensino e aprendizagem; utilização de conteúdos estáticos e de caráter universalista; na passividade do educando; e em práticas de memorização e repetição descontextualizadas, entre outras práticas (FREIRE, 1987, p. 33-35). Ele considera que a concepção bancária da educação nega a possibilidade do indivíduo ser mais, nega a possibilidade de transcender a realidade comum e criticar o fatalismo da condição dos que são oprimidos. Já a educação problematizadora, leva à libertação da consciência do indivíduo, caracterizando-se pela ação dialógica que permite ao educando um aprendizado significativo (FREIRE, 1987, p. 39). Assim:

A vocação para a humanização, segundo a
proposta freiriana, é uma característica que
se expressa na própria busca do ser mais
através da qual o ser humano está em perma-
nente procura, aventurando-se curiosamente
no conhecimento de si mesmo e do mundo,
além de lutar pela afirmação/conquista de
sua liberdade. Essa busca de ser mais, mas
não determinada por estruturas ou princípios
inatos. (STRECH; REDIN; ZITKOSKI, 2016,
p. 369)

Um ponto de convergência entre a pedagogia de Freire e a proposta pedagógica gramsciana é que ambas defendem a necessidade de uma educação ligada à vida, em que haja participação ativa dos educandos no processo educativo, cabendo ao educador auxiliar os educandos a questionar a realidade e unindo palavra e vida ao contexto cultural e histórico (FREIRE, 1987, 1996, 2006; GRAMSCI, 1999, p. 45). Enquanto Freire aborda problemas específicos da educação brasileira, como é o caso da educação de jovens e adultos, Gramsci apresenta uma proposta educativa ampla e sistemática, em que identifica aspectos como a formação humana, regime escolar, estruturação curricular, e a articulação entre educação e política em nível individual e coletivo inseridos no contexto italiano e mundial. As proposições de Freire para a organização da educação, contudo, se encontram fragmentadas na noção de conscientização e libertação.

\section{EdUCAÇÃo E POLÍTICA}

Para Freire o processo de conscientização permite ao indivíduo a conquista da autonomia (FREIRE, 1996), o que requer, invariavelmente, a superação da condição de oprimido e a percepção de sua "aderência ao opressor" (FREIRE, 1987, p. 17). Assim, cabe ao oprimido sobrepujar a "sombra do opressor" (FREIRE, 1987, p. 18), reconhecendo em si mesmo as marcas da opressão. Em Gramsci, a autonomia é o resultado da elevação moral e intelectual do indivíduo, o que permite a conscientização, processo semelhante ao proposto por Freire, onde se faz necessário reconhecer e superar as marcas do opressor em si mesmo. Na visão de Gramsci, tal processo permite a criação de um novo 
homem, um homem coletivo, que catalisaria as indignações individuais e ensejaria os princípios de uma revolução social.

Há diferenças, contudo, entre o conceito de oprimido de Freire e o de classe social de Gramsci. Gramsci não adota de forma generalizada o conceito de o oprimido. Ele se refere aos grupos sociais subalternos, abrangendo todos os que não são governantes. Em sua análise, ele adota ora o conceito de classe social, ora a noção de "grupos sociais". Buscava um conceito que não fosse vinculado apenas à estrutura econômica, mas também abarcasse a dimensão política, as relações de poder. Isso lhe permitiu uma leitura mais ampla da sociedade capitalista. Em Freire, não há distinção clara entre o conceito de oprimido e de classe social, sobretudo em sua obra Pedagogia do oprimido (FREIRE, 1987). Este fato é evidenciado pelo próprio autor. Em Pedagogia da esperança ele reitera sua noção de oprimido (FREIRE, 1992, p. 46), definindo o oprimido como indivíduo e classe ao mesmo tempo (FREIRE, 1992, p.29; STRECH; REDIN; ZITKOSKI, 2016, p. 294).

No âmbito político, enquanto Freire representa a tônica da "libertação", Gramsci representa a da conquista da hegemonia (SEMERARO, 2007, p. 95). Para alguns autores "libertação" e "conquista da hegemonia" são noções complementares porque envolvem a construção de um modelo de sociedade que leva em consideração as diferenças de classes e a busca pela igualdade social (MAYO, 2004, p. 94; SEMERA$\mathrm{RO}, 2007$, p. 103). O próprio Freire assume que em determinado momento de sua trajetória, o que chamou de "momento ingênuo", imaginou ser possível um processo educativo apolítico. No entanto, momentos depois compreendeu que "a educação é política", e, nesse sentido, "[a] educação é política e a política tem educabilidade" (FREIRE \& SHOR, 1987, p. 75-76).

Gramsci, por sua vez, em nenhum momento entendeu que a educação poderia ser apolítica. Sua atuação foi predominante política, tendo sido um dos fundadores do Partido Comunista Italiano, em 1921. Em sua trajetória intelectual, analisou a relação entre política e educação sob a ótica da hegemonia, o que fez com que negasse uma posição radical utópica, advinda do desejo apenas de libertação, para objetivar um realismo político manifestado na formulação de estratégias de organização social e partidária para a conquista da hegemonia das classes po- pulares nas sociedades contemporâneas (SEMERARO, 2007, p. 100). Na visão gramsciana a revolta ou a revolução, por si sós, não são capazes de alterar profundamente a estrutura da sociedade capitalista e criar novas concepções de mundo em todos os campos do conhecimento, bem como no plano ético e moral. Ele considera necessário elevar o nível intelectual e moral das massas populares e possibilitar a ruptura com as ideias dominantes introjetadas na consciência dos grupos subalternos.

Para Freire a transformação social ocorre com a libertação do oprimido de sua condição de opressão e na humanização dos opressores. Nessa perspectiva, não é necessário que o oprimido domine os instrumentos de dominação dos opressores, nem construa sua própria visão de mundo, pois ambos serão libertos por uma conscientização coletiva quanto ao caráter humano na busca por ser mais. Portanto, "[a] pedagogia do oprimido é, pois, liberadora de ambos, do oprimido e do opressor" (FREIRE, 1987, p. 05), cabendo aos oprimidos assumirem a posição de "restauradores da humanidade de ambos" (FREIRE, 1987, p. 16). Nesse aspecto de humanização, Gramsci considera que o "humano" não está concluído, a humanização é um processo em construção. Assim, não poderia ser "restaurado" o que ainda não tem uma configuração definida a priori.

Sobre a relação entre educação e política, Freire questiona os princípios da pedagogia do oprimido quando pergunta: "Se, porém, a prática desta educação implica o poder político e se os oprimidos não o têm, como então realizar a pedagogia do oprimido antes da revolução?" (FREIRE, 1987, p. 23). Os princípios adviriam da prática, da atividade dos oprimidos em desvelar o mundo:

A pedagogia do oprimido, como pedagogia humanista e libertadora, terá dois momentos distintos. O primeiro, em que os oprimidos vão desvelando o mundo da opressão e vão comprometendo-se na práxis, com a sua transformação; o segundo, em que, transformada a realidade opressora, esta pedagogia deixa de ser do oprimido e passa a ser a pedagogia dos homens em processo de permanente libertação." (FREIRE, 1987, p. 23)

Mas, a partir de que princípios os oprimidos iriam desvelar o mundo? Qual seria a orientação para isso? As respostas a essas questões 
não se encontram na obra de Freire, que evidencia em sua pedagogia o sonho, a utopia e o inédito viável como bases para o processo de transformação social. O inédito viável é a análise do real que nos permite pensar o inédito, transformando a ação em possibilidade concreta de modificação. Em outras palavras deve ser entendido não como a "[...] fronteira entre o ser e o nada, mas como uma fronteira entre o ser e o mais ser [...]" (FREIRE, 1987, p. 53). Em Freire a passagem de uma consciência ingênua para uma consciência crítica envolve a manifestação de uma conscientização política, evidenciada na práxis (ação + reflexão). Entretanto, essa noção de formação política ou formação para exercer atividades políticas é imprecisa, assumindo contornos romântico-idealizados, pois sua noção de "oprimido" e "opressor" é genérica. Para Freire, "vencida a irracionalidade, brotaria um comportamento 'orgânico', em sintonia com a realidade em mudança." (PAIVA, 1986, p. 133)

\section{PROBLEMATIZAÇÃO}

Seria a teoria da libertação em Freire um complemento à construção da hegemonia proposta por Gramsci? Seria este o ponto central de encontro entre o postulado de Freire e Gramsci? Embora não tenhamos a pretensão de responder ou esgotar esta questão em nosso texto, ambos os autores pensam uma sociedade igualitária onde as massas marginalizadas possam construir um Estado democrático-popular. Entretanto, enquanto Freire pensa uma sociedade balizada pela comunhão entre os homens, onde não existirão mais oprimidos e nem opressores, Gramsci observa a necessidade de uma reforma do ser humano, que envolve uma reforma individual e coletiva do homem. Não nos referimos aqui à noção de contra-ideologia ou à noção de construção de um pensamento contra-hegemônico, e, sim, à criação de uma nova ideologia que não possui como objetivo principal a negação da ideologia anterior, mas sim, a instituição de uma nova forma de pensar a sociedade.

Para Freire, a passagem de um estado de consciência ingênua para um estado de consciência crítica é mediada por um momento de transitividade da consciência (FREIRE, 1967, p. 59-60). Esse processo não é automático e requer um "trabalho educativo crítico com esta destinação" (FREIRE, 1967, p. 61). Apesar disso permanece a noção em Freire de que a modifi- cação do homem levará naturalmente à criação de novas visões de mundo, pois em seu trabalho não há um adensamento pragmático no que diz respeito às formas de implementação destes estados conscientes junto ao processo educativo.

Por vezes, a "imprecisão teórica" e o "insuficiente desdobramento de suas ideias" presentes em seus trabalhos até o ano de 1965 (PAIVA, 1986, p. 17) permitiu interpretações pessoais por parte de seus leitores de sua teoria do conhecimento, fundamentando a mudança na fé e na ideia de igualdade cristã. Em termos Hegelianos, para Freire a evolução da consciência é um meio de ligação a Deus, manifestando-se na noção de "espírito coletivo" (MARKUS, 2011, p. 527), ou, em termos especificamente freirianos, na comunhão entre os homens e no processo de humanização de opressores e oprimidos (FREIRE, 1987).

Embora Freire não mencione explicitamente este posicionamento em sua obra, esta leitura pode ser realizada devido ao seu vínculo com a igreja católica, na figura do Conselho Mundial de Igrejas (CMI) e na influência do existencialismo cristão em seu pensamento (PAIVA, 1986, p. 75). Segundo Freire, o homem encontra a ligação com seu criador no reconhecimento de sua finitude e transcendência. Portanto, o processo de religação a fonte criadora requer necessariamente um processo de libertação (FREIRE, 1967, p. 40).

Esse é um ponto central que diferencia o pensamento de Freire do de Gramsci: a relação do homem com o divido e o processo de transformação individual pelo qual este deve passar para instaurar uma nova sociedade. Enquanto em Gramsci o processo de transformação da sociedade assume uma ótica política de enfrentamento em Freire esta noção é marcada pela fé e pelo cristianismo. Dessa forma, para Freire, na medida em que as classes dominantes forem "penetradas pelo espírito cristão" haverá um processo natural de transformação (PAIVA, 1986, p. $57)$.

\section{CONSIDERAÇÕES FINAIS}

Paulo Freire e Antonio Gramsci foram grandes humanistas. Ambos formularam novas concepções de homem e de sociedade. Enquanto Gramsci concebeu a sociedade a partir de uma visão teórica que implicava a prática, Freire concebeu e analisou a sociedade de um 
ponto de vista prático, necessitando, posteriormente, de uma formulação teórica (FREIRE, 1987, 1992, 2006; PAIVA, 1986, p. 17). Segundo Paiva até 1965, Freire esteve absorvido por seu trabalho prático de criação de seu método de alfabetização e, portanto, teve pouco tempo para o trabalho teórico, assim enquanto sua prática avançava há um "atraso relativo da teoria" (PAIVA, 1986, p. 141). Em certo sentido, Gramsci escreve "[...] na posição de estrategista-analista político, enquanto Freire escreve, majoritariamente, com a perspectiva do pedagogo e do educador (MAYO, 2004, p. 89).

As maiores críticas ao pensamento de Freire são dirigidas ao seu método de alfabetização para adultos, entretanto a sua obra não pode ser limitada a aspectos específicos de seu método. O pensamento freiriano é amplo, evidenciado na sua pedagogia crítica em que aborda diversos temas relacionados aos saberes necessários à prática educativa (FREIRE, 1996). O trabalho de Freire não deve ser visto como uma "panaceia universal", "[...] mas como um instrumento, entre outros, a ser considerado na reflexão que serve ao fortalecimento da classe trabalhadora." (VANILDA, 1986, p. 13)

As possibilidades de aproximações teóricas entre o pensamento de Antonio Gramsci e Paulo Freire não se esgotam nos debates aqui focalizados. Apesar das diferenças dos contextos em que viveram e de suas concepções de sociedade, o pensamento desses dois autores possuem pontos de contato que ainda necessitam serem investigados com maior profundidade. Ambos analisaram o mundo com vistas à superação do ser humano e à construção de uma sociedade igualitária, principalmente para os menos favorecidos.

Apesar de proporem modificações a serem realizadas pelos indivíduos e transformações na sociedade, o modo como cada qual pensou as transformações a serem realizadas divergem fundamentalmente, como foi mostrado neste trabalho e, por isso, requerem maiores pesquisas e aprofundamentos teóricos. Enfim, esperamos que nosso trabalho tenha fomentado questões sobre as possibilidades de aproximações teóricas e práticas entre esses dois autores que influenciaram o pensamento educativo do século XXI.

\section{REFERÊNCIAS}

ABBAGNANO, N. Dicionário de filosofia. 5. ed. São Paulo: Martins Fontes, 2007.

\section{BARRETO, V. Paulo Freire para educadores. São Paulo: Arte e ciência, 1998.}

DORE, R. Atividade editorial como atividade educativa: reflexões de Gramsci sobre as revistas tipo. Revista de Sociologia e Política, v. 29, p. 79-93, 2007.

. Afinal, o que significa o trabalho como princípio educativo em Gramsci. Cadernos

Cedes, Campinas, v. 34, n. 94, p. 297-316, set.dez., 2014.

Texto introdutório produzido

para disciplina Paulo Freire e Antônio

Gramsci: Concepção de sociedade e proposta educacional. 2016. Material não publicado.

\section{FREIRE, P. Educação como prática de}

liberdade. Rio de Janeiro: Paz e Terra, 1967

Pedagogia do oprimido. 17. ed. Rio de Janeiro: Paz e Terra, 1987.

Pedagogia da esperança: Um

reencontro com a pedagogia do oprimido. Rio de Janeiro: Paz e Terra, 1992.

Pedagogia da autonomia: Saberes necessários à prática educativa. São Paulo: Paz e Terra, 1996.

Educação e mudança. 23. ed. Rio de Janeiro: Paz e Terra, 1999.

\section{Educação como prática da}

liberdade. 29. ed. Rio de Janeiro: Paz e Terra, 2006.

FREIRE, P.; SHOR, I. Medo e ousadia: o cotidiano do professor. Rio de Janeiro: Paz e Terra, 1987.

GRAMISCI, A. Cadernos do cárcere. Edição de Carlos Nelson Coutinho, com a colaboração de Luiz Sérgio Henriques e Marco Aurélio Nogueira. Rio de Janeiro: Civilização Brasileira, 1999, vol. 2. Caderno 2.

HEGEL, G. W. F. Fenomenologia do Espírito. 
Petrópolis: Vozes, 1988.

MARX, K. A ideologia alemã. 9. ed. São Paulo: Hucitec, 1993.

MARKUS, G. A ideia de Deus em Hegel.

Revista Aurora, Curitiba, v. 23, n. 33, p. 525537, jul./dez. 2011.

MAYO, Peter. Gramsci, Freire e a educação de adultos: Possibilidades para uma ação transformadora. Porto Alegre: ArtMed, 2004.

MESQUIDA, P.; ROSSETE, S. R.; PASCHOAL, G. de F. Paulo Freire e Antonio Gramsci ou A Filosofia da Praxis na ação pedagógica. (2006). Disponível em: <http://www.pucpr.br/ eventos/educere/educere2006/anaisEvento/ docs/Cl-202-TC.pdf> . Acesso em: 01 dez. 2016.

PAIVA, V. P. Paulo Freire e o nacionalismodesenvolvimentista. 2. ed. Rio de Janeiro: Civilização Brasileira, 1986.

SEMERARO, G. Da libertação à hegemonia: Freire e Gramsci no processo de democratização do Brasil. Revista Sociologia Política, Curitiba, n. 29, p. 95-104, Nov. 2007.

SILVA, P. C. D.; BARBOSA, C. L. Paulo Freire e Antonio Gramsci: aproximações. (2013) Disponível em: http://coloquio.paulofreire. org.br/participacao/index.php/coloquio/viiicoloquio/paper/viewFile/216/295. Acesso em: 20/06/2016.

STRECK, D.; REDIN, E.; ZITKOSKI, J. J. (Org.). Dicionário Paulo Freire. 3. ed. Belo Horizonte: Autêntica Editora, 2016.

\section{LIBERACIÓN VERSUS HEGEMONÍA: APROXIMACIONES ENTRE PAULO FREIRE $Y$ ANTONIO GRAMSCI}

Resumen: El estudio ha tenido como objetivo realizar aproximaciones teóricas entre las ideas de Paulo Freire y Antônio Gramsci, acerca de sus concepciones de sociedad y educación. Por lo tanto, nos preguntamos sobre las posibles relaciones entre estos autores, centrándose en los modos y caminos que definen para la transformación individual y social del hombre. En el campo de la educación, Gramsci presenta una propuesta amplia y sistemática, en que identifica la relación entre educación y política a nivel individual y colectivo. En Freire, estas nociones están fragmentadas en el sentido de conciencia y libe- ración. En el ámbito social mientras para Gramsci el proceso de transformación de la sociedad asume una óptica política de confrontación, en Freire esta noción está marcada por la fe y el cristianismo. Por fin, esperamos que nuestra pesquisa fomente cuestiones sobre las posibilidades de aproximaciones teóricas y prácticas entre esos dos autores que influyeron en el pensamiento educativo del siglo XXI.

Palabras Clave: Antonio Gramsci; Concepciones de educación y sociedad; Paulo Freire. 